\title{
LEIBNIZ ON FORCE, CAUSE AND SUBJECT OF MOTION: FROM DE CORPORUM CONCURSU (1678) TO THE BREVIS DEMONSTRATIO (1686) ${ }^{1}$.
}

\author{
RODOLFO FAZIO \\ https://orcid.org/0000-0003-0745-2643 \\ Universidad de La Frontera \\ Departamento de Ciencias Sociales \\ Facultad de Educación, Ciencias Sociales y Humanidades \\ Temuco, Chile \\ rodolfofazio@gmail.com
}

Article info

CDD: 193

Received: 11.08.2020; Revised: 30.09.2020; Accepted: 30.10 .2020

https://doi.org/10.1590/0100-6045.2021.V44N1.RF

\section{Keywords}

Leibniz

Force

Cause

Motion

Dynamics

\begin{abstract}
In the present paper we study the relationship between the notions of force, cause and subject of motion in Leibniz's early dynamics. First, we specify the role that the problem of the subject and cause of motion played in the development of his dynamics. Second, we analyze the distinction between force and quantity of motion and the validity and limits of his proof. Third, we study and evaluate the limits of the arguments for establishing that forces are inherent to bodies. Our main goal is to show that between 1678 and 1686 Leibniz dissociates the problem of the subject from the problem of the cause of motion and, furthermore, that even though the problem of establishing that
\end{abstract}

1 This research has been supported by Fondecyt Project \#3190696 (Chile)

Manuscrito - Rev. Int. Fil. Campinas, v. 44, n. 1, pp. 98-130, Jan.-Mar. 2021. 
force is inherent to particular bodies played a major role in the discovery of his dynamics, it has no place in its justification.

Leibniz's contribution to physics is generally overlooked in the history of science. Outshined by Newton's Principia mathematica philosophiae naturalis (1687), his writings on this matter are significantly less considered in the constitution of classical mechanics. Despite the fact that Leibniz did not have the same impact in natural philosophy as in other areas, such as mathematics or metaphysics, his works also play a role in the constitution of modern physics. In particular, his Brevis demonstratio erroris memorabilis Cartesii (1686) had an immediately impact and gave rise to the socalled living force controversy. It is usually accepted that D'Alembert's Traité de dynamique (1743) ended this debate, which, from that moment on, would be judged as a confused dispute over words proper to the dark times during which physics and metaphysics were still conflated. Nevertheless, some of Leibniz's ideas would remain: not only the name dynamics for the branch of physics dedicated to study the force of bodies (even though the force in modern physics is not measured in the Leibnizian way), but also the measure and conservation of the living force. ${ }^{2}$

Since the publication of Fichant's edition of De corporum concursu (1678), it has been accepted that Leibniz reached the distinction between force and quantity of motion almost ten years before the publication of the Brevis demonstratio. Indeed, in the former work he rejects for the first time the Cartesian measure of force as quantity of motion $(m|v|)$ and proposes an alternative measure $\left(m v^{2}\right)$. For this reason, modern scholars acknowledge De corporum

2 Leibniz's contribution to modern physics is summarized by Dugas (1950, pp. 460-521). For a general view of his position in the vis viva controversy, cf. Iltis (1971) and Shimony (2010).

Manuscrito - Rev. Int. Fil. Campinas, v. 44, n. 1, pp. 98-130, Jan.-Mar. 2021. 
concursu as the starting point of Leibnizian dynamics. ${ }^{3}$ However, it has been debated in recent decades whether the ideas established in 1678 are sufficient to establish a genuine dynamical theory. On the one hand, Robinet (1986, pp. 220-221) answers affirmatively. On the other hand, Duchesneau (1994, p. 122) claims that in 1678, although Leibniz already stated that force should not be measured as quantity of motion, we cannot properly speak of dynamics because in order to do so, an additional thesis must be demonstrated: that force is inherent to bodies and, therefore, they are the cause of motion. According to Duchesneau, Leibniz did not approach this issue in causal terms until 1686; therefore, the birth of dynamics would take place after the Brevis demonstratio and before the Dynamica de potentia (1690). In this paper, we study the roots

${ }^{3}$ Until the edition of De corporum concursu in 1994, it was difficult for scholars to understand Leibniz's transition from his first writings on physics to his mature ones. In particular, the reasons that led him to the introduction of dynamics as a new branch of natural philosophy were far from evident. For example, Gale (1988) claims that force is introduced for metaphysical grounds in the context of the Discours de métaphysics (1686). Similarly, according to Gueroult (1934, pp. 21-22), there is a gap between the principle of equipollency in 1676 and the relevant text on dynamics from 1686. For this reason, both scholars affirm that Leibniz's dynamics appears in 1686. Other authors, such as Hannequin (1907) or Belaval (1976, p. 76), conjectured the importance of the study of collision between bodies for understanding the birth of dynamics. Lacking the main primary text to ground their claims, they had to deduce it from other texts. In particular, Hannequin uses letters to Conring (GM I, 186) and Gallois (GP I, 202) in order to argue that the main thesis of Leibniz's dynamics must have been developed between 1678 and 1679. For the reception of De corporum concursu, cf. DCC, 9-13).

Manuscrito - Rev. Int. Fil. Campinas, v. 44, n. 1, pp. 98-130, Jan.-Mar. 2021. 
of Leibniz's dynamics and claim that between the $D e$ corporum concursu and the Brevis demonstratio, he assumes in his physical writings the task of proving not only that force and quantity of motion should be measured in different ways, but also that bodies themselves are the subjects that exert that force. Indeed, during these years Leibniz attempts to prove that bodies are causally active and, therefore, to criticize occasionalism based on empirical considerations of natural philosophy. However, as we will show in our paper, this attempt fails and, as result, Leibniz differentiates the problem of the subject from the problem of the cause of motion: the a posteriori argument only demonstrates that force of motion should be estimated differently from its quantity, but do not resolve the issue of which subject is exerting or producing that force. In other words, we believe that despite the proximity that the notion of cause and subject could have from a metaphysical point of view, Leibniz's dynamics do not need true agency in bodies, that is, it is compatible with occasionalism insomuch it only relies in the possibility of studying motion from a causal approach ${ }^{4}$. In this sense, we argue that, even though the problem of establishing that force is inherent to bodies played a central role in the discovery of Leibnizian

4 Leibniz introduced the term dynamics in 1686. In the classification of sciences proposed in Guilielmi Pacidii (1986), he included in his enumeration "dynamic or [the study] of the cause of motions, or of cause and effect, potency and act" (A VI; 4, 676). However, in this paper we use the name to refer to all Leibniz's writings on this subject from 1678 onwards. We understand it as the science that study motion from a causal approach (differently from cinematic that considers motion from a mathematical point of view as mere change of place).

Manuscrito - Rev. Int. Fil. Campinas, v. 44, n. 1, pp. 98-130, Jan.-Mar. 2021. 
dynamics, it has no place in its justification, leaving the debate with occasionalism exclusively to metaphysics. ${ }^{5}$

To this end, we divide our work in three sections. First, we study the context that led to the distinction between force and quantity of motion; in particular, we explain the main theses of Leibniz's natural philosophy before 1678 and specify the role that the issue of the cause and subject of motion played in the birth of his dynamics. Second, we analyze Leibniz's distinction between force and quantity of motion presented in De corporum concursu and the Brevis demonstratio. Third, we evaluate Leibniz's arguments for establishing that forces are inherent to bodies between 1678 and 1686 and we conclude that after those years he realized that the difference between force and quantity of motion

${ }^{5}$ After the publication of the Brevis demonstratio in 1686, Leibniz dedicated much of his time to debate the a posteriori argument in favor of the distinction between force and quantity of motion. The debates on this proof with Cartesians such as Catelan, Papin, or De Volder obliged him to undertake a great effort to go into detail about other physical issues: fundamentally, the cause of gravity, the principle of continuity, and the elasticity of bodies (themes involved in Leibniz's different formulations of the $a$ posteriori proof). In the context of this debate, Leibniz designed a new proof with the hope of ending the debates with Cartesians: an a priori one. Although this argument was the last that Leibniz presented, he valued it greatly "for it does not employ weight, or elasticity, or any other hypotheses or accidental features, but arises most clearly from primary and maximally abstract notions" (GP II, 174). In relation with Leibniz's general philosophy, the $a$ priori argument has proved attractive to many scholars: given the abstraction of physical hypotheses, it seems to be in touch with some basic metaphysical themes. In our paper we do not consider the possible benefits of the a priori version; we only evaluate the scope and limit of the a posteriori one and its role in the constitution of Leibnizian dynamics between 1678 and 1686, that is, until the publication of the Brevis demonstratio. 
do not necessary solve the problem of which subject is indeed the cause of motion.

\section{Leibniz's natural philosophy before De corporum concursu: the relativity of motion and the principle of conservation of force.}

The first issue we want to address is why Leibniz began a work in 1678 dedicated to studying the laws of impacts between bodies. His interests on this subject date at least from 1669, when he first took notice of Huygens's and Wren's equations for collision. His first thoughts on this subject can be found in the Theoria motus abstracti (1671). However, between this early writing and De corporum concursu Leibniz introduced some fundamental changes into his natural philosophy, consequences of the encounter with Huygens during his years in Paris: indeed, he was responsible not only for introducing Leibniz to Cartesian physics and modern mathematics, but also for motivating the young German to revise his account of motion ${ }^{6}$. Two major changes can be found in Leibniz's natural philosophy as result of this encounter. On the one hand, from 1675 onwards Leibniz abandoned the absolutist conception of motion and assumed a relativistic approach. On the other hand, he understood the role of the principle of conservation in physics: from 1676 this principle would be considered the fundamental axiom that grounds all physical law. We maintain that these two changes help to explain

\footnotetext{
${ }^{6}$ For a comparison between Huygens and Leibniz's conception of relative motion, cf. Bernstein (1984). It is also worth noting that Huygens was the responsible for introducing Leibniz for the first time to infinite series. On this subject, cf. Hofmann (1949, pp. 21-22) y Antognazza (2009, p. 142-144).
}

Manuscrito - Rev. Int. Fil. Campinas, v. 44, n. 1, pp. 98-130, Jan.-Mar. 2021. 
why after his time in Paris Leibniz applied himself to a systematic study of the laws of collision in De corporum concursu and, furthermore, why the structure of this text led him to the distinction between force and quantity of motion.

Until 1672, Leibniz maintained an absolute theory of motion; namely, he claimed that motion is the change of position of a body in relation to space (cf. A II, 1, 34; A VI, $2,167)$. Although he does not present any argument to defend such a claim, he could assume it because his ontology allowed it. In fact, absolute motion is possible in the philosophy of the young Leibniz because he argues that space exists as something distinct from the bodies that occupy a place in it; this thesis is claimed in many texts between 1668 and 1672, such as the correspondence with Thomasius (A II, 1, 11) or the Specimen demonstrationum de natura rerum corporearum ex phaenomenis (1671) (cf. A VI, 2, 305). Thus, since space is different from bodies, Leibniz judges that the speed and direction of a body can be established in relation not to other bodies, but to space itself, which works as an absolute frame of reference. In a letter to Oldenburg from 1671, he distinguishes himself from Descartes on this point: "I do not concede to Descartes that motion consists only in the change of proximity [mutatio vicinitatis]" (A II, 1, 272). ${ }^{7}$

However, during 1672 and 1676, Leibniz changed his mind and committed himself to the relativistic conception of motion. In the Principia mechanica (1673-1675), he set forth his main arguments to prove that in any kind of movement, not only in uniform rectilinear motion, but also in accelerated and circular motion, it cannot be established which body is in motion and which is at rest in absolute terms, namely that "from the mere phenomena of change

${ }^{7}$ For Descartes's definition of motion, cf. AT VIII, 53. 
of position it cannot be obtain a true knowledge about the absolute motion and rest" (A VI, 3, 110). In order to prove this, Leibniz uses the method of equivalent hypotheses, which consists of explaining one variation of distance between bodies with two equivalent frames of reference, but considering that the same body moves in one of these frames and stays at rest in the other. Since Leibniz argues that we can always make both hypotheses salva veritate (namely, explaining the phenomena accurately), absolute definition should be abandoned in natural philosophy because which body is in motion and which one is at rest can be modified according to the frame of reference we choose. Although Leibniz states that we should always prefer the simpler hypothesis, that is, the frame of reference that explains the variations of distances supposing fewer bodies in motion, it is always possible to make other hypotheses that are equally valid. ${ }^{8}$

As a consequence of his years in Paris, Leibniz assumed that motion is not an absolute state or predicate of particular bodies, but a state or predicate of multiple bodies that change their relations one to each other. From a more philosophical point of view, this thesis opens a new problem that was absent in the philosophy of his earlier years: since it cannot be established which body is in

\footnotetext{
${ }^{8}$ In Principia mechanica, Leibniz affirms that the criterion to choose between different hypotheses is pragmatic: "we have to choose the explanation that allows us to find a cause from which it can be derived more easily the other changes" (A VI, 3, 110). He therefore holds that Copernicus's heliocentric system must be preferred to those of Ptolemy or Tycho Brahe, since by moving only one body we can explain all phenomena. In writings like $D e$ praestantia systematis Copernicani (1689), Leibniz argues that even though absolute motion cannot be established, "the Copernican hypothesis is the more simple and, for that reason, I accept it as truth" (A VI, 4, 2072).
} 
motion by the mere change of position, Leibniz began inquiring whether the cause of that change is determinable in any other way. In Quod motus sit ens respectivum (1677), he declares:

"A remarkable fact: motion is something relative, and one cannot distinguish exactly which of the bodies is moving (...). It should be noted, however, that when we consider motion not formally as it is in itself, but with respect to cause, it can be attributed to the body of that thing by whose contact change is brought about' (A VI, 4, 1970).

Although it is impossible to establish which body is in motion or at rest since change of distance is only a variation of relative position, Leibniz claims we can determine which body is the cause of that change when we consider the collision of bodies. Already in Physicae partes (1677), Leibniz seems to reserve a place for dynamics: "the study in physics is double: one about the forms or affections considered isolated [that is, movements], and another about the subject in which concur those multiple affections" (A VI, 4, 1960). We will come back to this idea in the third section of the paper. For now, we are interested in the fact that the problem of establishing which body is the cause of motion was the main reason that led Leibniz in 1677 to return to the study of the law of impact and, therefore, to write $D e$ corporum concursu in January of 1678. In summary, the causal approach to mechanics, far from being absent among his concerns, constituted the main issue that led him to write a systematic text on the topic. ${ }^{9}$

9 For an interpretation of this group of texts in relation to Leibniz's dynamics, cf. Garber (2009, pp. 111-115).

Manuscrito - Rev. Int. Fil. Campinas, v. 44, n. 1, pp. 98-130, Jan.-Mar. 2021. 
In order to give proper context for De corporum concursu we must present a second main idea that Leibniz also learned in Paris: the fundamental role of the conservational principle in physics. Between 1672 and 1676, Leibniz introduced no particular changes to natural philosophy, but he did modify the way he thought it should proceed. Instead of studying the problem of impact between bodies, as in 1671 or 1677 , he addressed a more general issue: that of the law. In particular, he looked into the basic truth that is assumed in physics in order to establish the different laws of motion. The first text dedicated to this issue is De arcanis motus et mechanica ad puram geometriam reducenda (1676). Taking as valid all these different laws that describe the motion of bodies in different circumstances, Leibniz seeks to understand the common principle that ground them all:

"It is necessary that the laws of motion, many of which have been discovered to the present day, should be reduced to a principle in virtue of which they can be formulated in some analytical equations" (A VIII, 2, 133).

Regardless of the particular formulation of the law, Leibniz accepts that, for example, physicists like Huygens arrived to equations that accurately describe how a body descends in a pendulum, that is, which is its position at any time. In $D e$ arcanis motus, Leibniz claims that this particular law is grounded in a more basic and fundamental one: that if there are no external impediments, the pendulum should reach the same height at the end it as had at the beginning, neither more nor less. ${ }^{10}$ In a more general way, Leibniz's

10 This principle was explicitly formulated by Huygens in 1669 and applied to the case of pendulum in Horologium oscillatorium (1673); cf. Gueroult (1967, pp. 28-29 and 93). Leibniz usually 
main idea is that if it is possible to describe the successive positions of body with an equation, something should be equivalent through time.

Despite the difference that exists between physics and mathematics, during these years Leibniz seems to consider analogous the way both science should ground their particular truths in a general equivalence. In particular, he states that in order to reduce the laws of physics to analytical equations, one must have equality between the parts. In mathematics, equality is guaranteed, according to Leibniz, by Euclid's axiom, which establishes that the sum of the parts is equal to the whole: one number can be divided in infinite ways, but Euclid's axiom guarantees that nothing is lost. Leibniz maintains that this principle of conservation of quantity is the fundamental truth of mathematics that lies behind all its equations, from basic sums as $4=2+2$ to infinite sums as $\pi / 4=1-1 / 3+1 / 5-1 / 7+1 / 9 \ldots$. However, in physics, the situation is slightly different because natural philosophy works with successive events, that is, states that cannot coexist simultaneously. For that reason, Leibniz claims that the fundamental equivalence in natural philosophy is not between whole and parts, but between cause and effect.

"Such as in geometry the principle of reasoning consists in the equality between the whole and the sum of its parts, in mechanics all depends on the equality between the whole cause and the total effect. Therefore, such as

exemplifies the principle of conservation of force with the case of pendulum: "for example, the pendulum will return precisely to the height from which he departs if nothing of its impulse were absorbed by the resistance of the air and other similar impediments" (A VI, 4, 2028). 
the primary axiom of geometry is that the whole is equal to the sum of its parts, the primary axiom in mechanics is that the potency of the whole cause and the potency of the total effect is the same" (A VIII, 2, 135). ${ }^{11}$

First of all, Leibniz defines potency or force in this way: "potency is the state from which, given certain circumstances, it follows an effect of a determined quantity" (A VIII, 2, 136). To continue with our example of the pendulum, the principle of conservation of force (which Leibniz refers to as the principle of equipollency or equipotency) states that at the end of its movement, the pendulum reaches a state in which it has the capacity to return to the original one: the total effect is equal to the whole cause because the variation of distance that the pendulum can produce at its initial state is the same that it can produce at its final state. In Leibniz's terms, "the total effect can reproduce the entire cause; the effect can reproduce itself" (A VIII, 2, 136). According to Leibniz, this fundamental equality lies behind all the laws of motion and allows for their analytical equations: not only does it work for the case of a pendulum, but also for statics, freefalls, collisions, oscillations, etc.

Although the conservation of force remains the fundamental axiom of physics in his mature writings, before De corporum concursu Leibniz understands force or

11 Wallis's Mechanica sive de motu tractatus geometricus (1670) is the main influence of Leibniz on this subject. In relation to this subject, Leibniz's innovation lies in claiming not the proportionality but the equality between cause and effect. He emphasizes this point to Bayle in 1687: "[the principle of conservation of force] does not say only that the effects are proportional to its causes, but that each entire effect is equivalent to the causes" (GM III, 46). Cf. Garber (2009, pp. 103-104).

Manuscrito - Rev. Int. Fil. Campinas, v. 44, n. 1, pp. 98-130, Jan.-Mar. 2021. 
potency in a peculiar way. In fact, he defends that it should be measure in the Cartesian way:

"it was easy to judge that the efficient cause of phenomena should consist only in the quantity of body and its speed" (A VIII, 2, 134).

With force defined as "the state from which, given certain circumstances, it follows an effect of a determined quantity," until 1678 Leibniz judges that the effect should be measured by what Cartesians define as quantity of motion, that is, the scalar product between the quantity of body and its speed $(m|v|) . .^{12}$ Furthermore, Leibniz acknowledges that Descartes was one of the few to observe the conservation of force in nature (cf. A VI, 3, 466).

De corporum concursu is written following this main idea, namely that the laws of motion (included collisions) are grounded in the conservation of force and that this force is

12 Leibniz's interpretation of Descartes is controversial on this point. In fact, Descartes does not seem to make the mistake that Leibniz criticizes. Descartes introduces the notion of quantity of motion in Principia philosophiae as an absolute quantity that is conserved in the universe (Principia Philosopbiae II, 36). But he does not identify this concept with the force of bodies. In fact, Descartes introduces force in relation to the problem of collision of bodies (Principia Philosophiae II, 43). Different from quantity of body, force is something relational that is established only in collision between bodies and, for example, implies direction. Descartes seems to think of force as a vectorial magnitude. Descartes recognizes the difference between these two notions in his letter to Clerselier of 17 February, 1645 (AT IV, 185). Nevertheless, during the second half of the $17^{\text {th }}$ century, Cartesians made the equivalence questioned by Leibniz. In this sense, the error does not belong to Descartes himself, but to Cartesians such as Nicolas Poisson. 
equivalent to the quantity of motion of bodies. Indeed, in the first section of De corporum concursu Leibniz establishes the conservation of quantity of motion as the first principle of natural philosophy and in the next ten sections he studies all the possible combinations of collisions. However, this attempt will teach him a problem with the Cartesian understanding of conservation. Indeed, the first paragraph and his marginal note, added after he concluded the work, shows the general conclusion of this writing:

"In all type of motion the same force is always conserved. Force is the quantity of effect or, from its consequence, the product between the quantity of body and speed [Leibniz's marginal note: Error: this conclusion is invalid in our system]" (DCC, 71).

The problem with the Cartesian measure of force appears in the sixth section, in which Leibniz studies the collision between bodies of different sizes in a pendulum. After studying different cases from it, he concludes that there is a vis perdita, that is, the total quantity of motion diminishes in the system. ${ }^{13}$ It is worth observing that the problem arises when the laws of impact are considered simultaneously with the laws of free-fall and the laws of oscillation. In other words, the problem of Cartesian measure of force arises when he attempts to achieve a systematic treatise of impact that could unite all different particular laws that physicists developed during the first half of $17^{\text {th }}$ century under one common principle.

In sum, the impossibility of establishing motion as an absolute state of particular bodies is the main reason that

13 For an analysis of this proof, cf. Duchesneau (1994, pp. 123$130)$.

Manuscrito - Rev. Int. Fil. Campinas, v. 44, n. 1, pp. 98-130, Jan.-Mar. 2021. 
historically leads Leibniz to consider the laws of collision: he believes that this case could determine in absolute terms which body is the cause of motion. On the other hand, Leibniz's considerations on the role of the principle of conservation change the way he structures his physical system and, as we will see in the next section, lead to his main discovery: that force should not be measured as quantity of motion.

\section{Leibniz' distinction between force and quantity of motion.}

Before analyzing Leibniz' distinction between force and quantity of motion, it is important to note that De corporum concursu left him a double lesson. First, Leibniz learned that the laws of impact are not compatible with Cartesian conservation of quantity of motion. Second, he learned that force can be estimated in another way. Indeed, Leibniz did not seek to reject either the laws of impact or the conservation of force, but only the equivalency between force and quantity of motion as Cartesians understood it $(m|v|)$. In one of foundational passage of Leibnizian dynamics he claims:

"[Leibniz's commentary] I see where the mistake lies. The force should not be estimated by the speed and the quantity of body, but by the height from which it falls. Besides, the height from which bodies fall is equivalent to the square of their speed. Therefore, the force is also like that, if we suppose that the bodies are equal. In consequence, the forces are generally composed by the simple product of bodies and the square of their speed. Therefore, two bodies have the same force not as 
people generally think, namely, when the speed is reciprocally to the quantity of bodies, but when the square of the speed is reciprocally to their quantity. Thus, it is evident that the same quantity of motion is not conserved, but only the same force" (DCC, 134).

Leibniz maintains the principle of conservation of force and the general idea that force should be estimated by the quantity of the effect that a body could produce. Nevertheless, from 1678 onwards he claims that the effect should not be estimated by the quantity of motion $(m|v|)$, but in another quantity: $m v^{2}$. On the one hand, Leibniz's innovation does not lie in any of the particular theses of $D e$ corporum concursu. First, he repeats the laws of motions accepted by the natural philosophers of his time. Second, the conservation of $m v^{2}$ was proposed by Huygens in 1669, and Leibniz learned of it that year. ${ }^{14}$ However, Leibniz's originality lies in the place that the conservation of force as $m v^{2}$ occupies in his physical system: he elevated it to the constant magnitude that is conserved in all systems of bodies. On the other hand, this change of measure is proposed as a correction that allows subsuming the empirical laws of impact under the principle of conservation, for the different types of motion, such as falls, impacts, oscillations, etc., cannot be integrated under the estimation of force as $m|v|$, but only as $m v^{2}$. It is worth noting that Leibniz's metaphysics does not play a specific

\footnotetext{
${ }^{14}$ In 1669 Huygens already claims that "the sum of the products between the quantity of each hard body and the square of their speed is the same before and after the impact" (Huygens, XVI, 180). Since Huygens understands conservation of quantity of motion as $m v$ and not $m|v|$, he requires a scalar magnitude such as $m v^{2}$ in order to explain conservation in frontal collisions.
} 
role for establishing the correct measure of forces. With this thesis we do not want to reject or undermine the role assigned to metaphysics for grounding natural philosophy, but only to identify in which sense physics remains autonomous. Indeed, from his youth to his mature writings Leibniz claims that the principles of physics cannot be demonstrated within natural philosophy itself: metaphysics is the responsible for establishing them. For example, natural philosophy considers the principle of equipollence as a fundamental axiom and a primitive truth, but first philosophy should assume the task of establishing that principle from more fundamental and basic truths. In this sense, even though we believe that problems such as how forces should be measured are resolved within physics itself, this autonomy does not nullify the fundamental role of metaphysics for grounding its principles.

In order to understand the distinction between force and quantity of motion, we will work with the Brevis demonstratio not only because it contains an easier argument than De corporum concursu (it does not consider the impact nor the pendulum but arrives to the same conclusion considering only free-fall), but also because it is the proof that Leibniz decided to make public. The argument can be summarized in these steps:

1. One body that falls from a certain height acquires the force necessary to come back to the same height, no more and no less (principle of conservation of force)

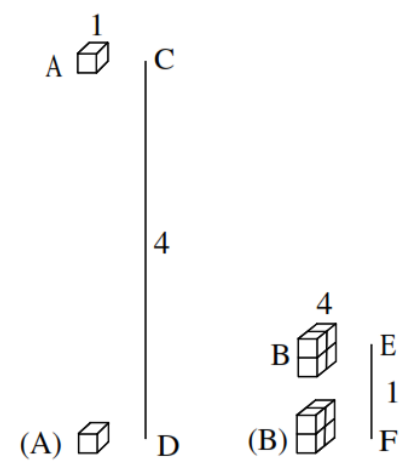

Manuscrito - Rev. Int. Fil. Campinas, v. 44, n. 1, pp. 98-130, Jan.-Mar. 2021. 
2. This force can be measured as quantity of motion $(m|v|)$.

3. The same force is required to elevate a body $\mathrm{A}$ of 1 pound to height $\mathrm{CD}$ of 4 fathoms as is required to elevate a body $\mathrm{B}$ of 4 pound to the height EF of 1 fathom. ${ }^{15}$

4. The forces required to elevate $\mathrm{A}$ to $\mathrm{C}$ and $\mathrm{B}$ to $\mathrm{E}$ is equal to the force that $\mathrm{A}$ acquires by falling from $\mathrm{C}$ to $\mathrm{D}$ and that $\mathrm{B}$ acquires by falling from $\mathrm{E}$ to $\mathrm{F}$ (derived from step 1 and step 3).

5. Galileo's free-fall laws establish that body A acquires in CD double the speed of B in EF. ${ }^{16}$ Therefore, body A reaches a quantity of motion at $\mathrm{D}$ equal to 2 $\left(m\left|v_{1}\right|=1.2\right)$, and the body B has a quantity of motion equal to $4\left(m\left|v_{2}\right|=4.1\right)$.

6. There is a contradiction between step 4 (A and $\mathrm{B}$ have equal forces), step 5 (A and B have different quantities of motion), and step 2 (the equivalence between force and quantity of motion).

7. Conclusion: force cannot be measured by the quantity of motion (rejection of step 2).

15 Cf. Gueroult (1967, p. 61). Descartes refers to this principle in a letter to Constantin Huygens of 1637 (AT I, 435-436) and in his correspondence with Morin (AT II, 229) and Mersenne (AT II, $353,432)$. It is also used by Pascal in the Traités de l'équilibre des liqueurs (1663).

${ }^{16}$ Leibniz uses the law of free-fall established by Galileo in the Discorsi e dimostrazioni matematiche intorno a due nuove scienze (1638), in which he proves that the distance that a body travels from a certain height is proportional to the square of time $\left(b=t^{2}\right)$, while speed is proportional to time itself $(v=t)$; therefore, distance is proportional to the square of speed $\left(h=v^{2}\right)$.

Manuscrito - Rev. Int. Fil. Campinas, v. 44, n. 1, pp. 98-130, Jan.-Mar. 2021. 
8. Corollary: Force is the quantity of effect that a body can produce, that is, the height to which it elevates, which is proportional not to its speed, but to its speed squared.

From this argument, Leibniz concludes that "there is a big difference between force and quantity of motion, so that one cannot be measured by the other, and that is what we try to demonstrate" (A VI, 4, 2029). Similarly to De corporum concursu, Leibniz's only original step is the conclusion. Indeed, the other theses are taken from other authors (Descartes, Pascal, and Galileo). His innovation lies only in grouping them all together.

Classical interpreters such as Mach (1883) and Iltis (1971, 27) saw in Leibniz's argument a pretension of proving that force, measured as $m v^{2}$, is conserved in nature. In this case, however, such an argument would be invalid because this conclusion cannot be demonstrated by the simple case of the Brevis demonstratio, rather, it requires some additional hypotheses, such as the elasticity of all bodies (for $m v^{2}$ is not conserved if the bodies that collides are absolute rigid; it is only valid in percussions). Indeed, Leibniz claims that force is conserved in nature and, therefore, that all bodies are elastic, but those theses did not follow from the previous argument. On the one hand, the conservation of force is not the proof's conclusion but its premise. On the other hand, Leibniz rejects from 1678 onwards the notion that the conservation of force could be demonstrated in the same way as the distinction between force and quantity of motion. In fact, he holds that it can be proved, but not within the science where it is used: for him this is an issue for metaphysics rather than physics. In physics, the conservation principle works as a heuristic or architectonic principle that allows us to understand phenomena but it is not founded in these phenomena. In metaphysics, Leibniz holds that the conservational principle 
can be demonstrated not from geometrical reasons but from final and moral ones. As Brown (1984) points out, the objective of the Leibnizian argument is to show an error made by Cartesian physicists, namely the equivalence between the measures of force and quantity of motion. As Leibniz declares to Catelan in the first episode of the vis viva controversy: "I showed with a pretty ordinary case [namely the free-fall of bodies] (...) that two bodies have the same force, but not the same quantity of motion; you concede it, and I do not ask for more" (GP III, 43). As Brown (1984) states, Leibniz did not seek to prove the conservation of force nor reject conservation of the quantity of motion, but rather only proposed the minimal thesis that both magnitudes should be measured in different ways. Indeed, understanding this minimal objective of Leibniz's proof is necessary in order to guarantee its validity.

In formal terms, Leibniz's argument is a proof by contradiction in which he assumes some propositions and shows that when they are all considered together, an inconsistency emerges. But why did he decide to reject step 2 of the argument in order to avoid this contradiction? In principle, it could be avoided in others ways, namely by rejecting another of the non-derived steps. However, despite the fact that there are not conclusive reasons to arrive to his conclusion, we can understand why he preferred it. Indeed, the other steps of the argument are not easy to reject: step 1 is the principle of conservation, step 3 refers to a particular law established by Pascal and Descartes for studying the behavior of bodies in hydrostatic and step 5 uses Galileo's law of free-fall. Leibniz did not doubt of the conservational principle for the reasons given in the first section of this paper; and the particular laws of Pascal, Descartes and Galileo work well, and Leibniz did not wish to change them. Furthermore, Leibniz had an alternative measure of force that resolved the issue and 
worked better than the Cartesian measure because it was valid for all kinds of physical systems.

During the $17^{\text {th }}$ century, Leibniz's proof received some objections, particularly from Cartesians. The first was proposed by Catelan in September of 1686. He claimed that the argument fails because it only works if the two bodies fall at different times, while the Cartesian principle of conservation of quantity of motion is valid when we consider "isocronic potencies, that is, movements impressed in equal times" (GPIII, 41-42). Therefore, if we consider the fall of the two bodies during the same time, they will have the same quantity of motion. ${ }^{17}$ The objection is poor but it helps to understand the argument of the Brevis demonstratio. In his answer to Catelan, Leibniz explains that the force acquired by a body in a fall is independent of the time that that body needs to travel that distance. As a counter-example, he shows that his proof can be modified in order to satisfy Cartesian exigencies because the bodies can travel their distance in the same time by changing the inclination of the fall of one of them:

"I think that in this case the present state can be known without regarding the past ones. When there are two perfect equal and similar bodies, and they have the same speed, but one acquires it by a fast impact and the other descending a long time, would those bodies have different forces? It would be similar to say that is richer a man that has made his fortune in considerable time. But, it is not even necessary that the two bodies travel their different height in different times, such as Catelan supposed, because he did not

17 For Catelan's objection, cf. GP III, 41-42. 
considered that the time of the fall can be changed if we modify the inclination of the movement; and there are infinite ways in order to make that the two bodies fall from their different height in equal times. For, if we do not consider the resistance of air and similar obstacles, it is known that a body that falls from a certain height acquires the same speed in a perpendicular fall or in a slower and more inclined one" (GP III, 44).

In other words, the speed that a body acquires in a fall depends exclusively on the height and not on the time needed to travel it. Thus we can modify the example in order to make both bodies travel their different distances in the same time and the conclusion will remain the same: their forces cannot be estimated by their quantity of motion.

Furthermore, the distinction between force and quantity of motion is of particular interest to Leibniz because he opens a new way to study the problem of subject and cause of motion. In his debate with Catelan, Leibniz claims that:

"Force should not be estimated by the speed and quantity of body, but by its future effect. However, it seems that the force or potency is something real in the present, but the effect is not. From that it follows that we have to admit in bodies something different from their quantity and speed, unless we want to negate to them all potency of action" (GP III, 48).

In this short passage, Leibniz recognizes the two main philosophical interpretations that can be made of the distinction between force and quantity of motion: on the 
one hand, to claim that the force is in the bodies, which would be the real causal agent of change; and on the other hand, to affirm that although the force is real in bodies, they are not the cause of that action (that is, occasionalism). In the next section, we will analyze the first arguments that Leibniz presents in favor of the former position.

\section{The subject and cause of motion between De corporum concursu and the Brevis demonstratio.}

The distinction between force and quantity of motion allow us not only to improve the formulation of the principle of conservation, but also to attempt a new solution to a problem connected with Leibniz's more fundamental inquiries, namely the issue of the subject and cause of motion. It is worth noting that in the years prior to publication of the De corporum concursu, Leibniz gave a peculiar answer to this problem. In particular, between 1676 and 1677, he adopted a solution quite close to occasionalism. For example, in the Pacidius Pbilaleti (1676), he declares that for the case of the impact of two spherical bodies: "what moves and transfers the body is not the body itself, but a superior cause which does not change by the action, which we call God" (A VI, 3, 567). Another strong claim can be found in Quod motus sit ens respectivum (1677): "A remarkable fact is that motion is something relative and it cannot be distinguished exactly which of the bodies moves; thus if motion is an affection, its subject will be not one individual body, but the whole world" (A VI, 4, 1970) ${ }^{18}$. We believe that this position can be understood if we consider two main theses he defended in 1676-1677: the general relativity of motion and, simultaneously, the

18 We follow Garber (2009, 190-193).

Manuscrito - Rev. Int. Fil. Campinas, v. 44, n. 1, pp. 98-130, Jan.-Mar. 2021. 
absolute conservation of its quantity. Those theses combined lead to a situation in which motion is an absolute quantity in the whole system, but we cannot establish which particular body produces which particular change; therefore, Leibniz tried to answer the issue by assuming that the subject of this predicate is the entire world with God the only causal agent in it. However, since the introduction of force as something different from quantity of motion, Leibniz proposed a different solution that can be found in the texts that follow De corporum concursu, such as Specimina de motus causa et de corporum qualitatibus (16781680/1) and Principia mechanica ex metaphysica dependere (1678$80 / 1)$. The general idea is that, unlike motion, force can be determined as a magnitude that pertains to a particular body independently of the frame of reference we choose and, in that sense, it can escape from general relativity. In this section, we analyze the two arguments in Specimina de motus causa et de corporum qualitatibus and claim that neither of them is conclusive.

In his first argument, Leibniz attempts to show that even though motion consists of a relative variation of distance between bodies and it cannot be established which body is in motion and which is at rest, when a body impacts another, its force can be measured independently of the frame of reference we choose and, therefore, we can establish which body introduces the change:

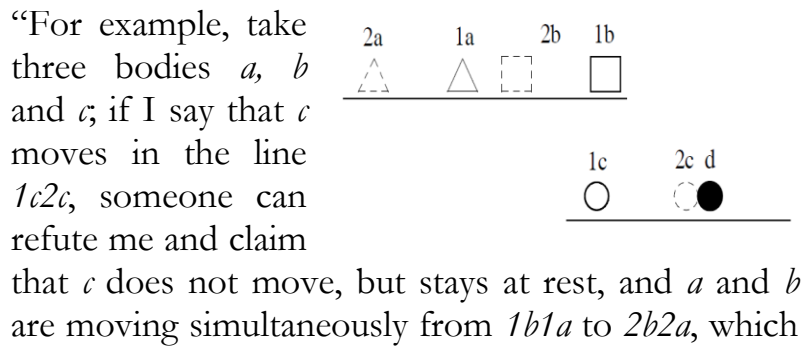


is valid.Although it is not probable (for it is more simple to suppose one movement than two), it is nevertheless possible. For if we suppose that the first position is $1 a 1 b 1 c$ and the movement is $1 c$ to $2 c$ and $1 a$ and $1 b$ stay at rest, then the phenomena that results will be the position $1 a 1 b 2 c$; and if $1 c$ stays at rest and the movement is $1 a 1 b$ to $2 a 2 b$, then the phenomena that results is $2 a 2 b 1 c$, which cannot be discerned a priori from the phenomena or position $1 a 1 b 2 c$. Therefore, it cannot be judged from that which of the hypotheses is true. The same happens if we suppose four bodies instead of three, in which case the phenomena could be explained by more hypotheses. But if we assume a new body $d$ in a way that, when $c$ moves from $1 c$ to $2 c, c$ will necessary impact $d$, then we pass from the simple mathematical consideration of change of situation to physics, that is, to some action, because [from impact] it follows a communication of motion from which it is evident that some action should be ascribed to body c" (A VI, 4, 2018)

Leibniz claims that body $c$ could be considered in motion or at rest in relation to the other bodies of the system and he repeats the same kind of argument as is present in Principia mechanica: from considering the mere change of position, it cannot be discerned if a body is in motion or at rest since we can always make equivalent hypotheses in order to explain one and the same variation. However, in this text, Leibniz claims that if we consider the collision between two bodies, we can establish which body is the cause of the variation of distance. First of all, it is true that Leibniz states that when we consider motion in relation to its cause, we can establish which body is producing the change. 
Nevertheless, this consideration does not break with the general relativity of motion because we can still make a hypothesis in which the body that exerts the action remains at rest $\mathrm{t}^{19}$. Indeed, Leibniz is explicit on this matter. For example, he claims to Huygens in 1694 that "Newton accepts the equivalence of hypothesis for rectilinear motion, but he believes that in circular motion the effort of bodies that rotate in order to go away from the center or axe of rotation would allow us to identify its absolute motion; but I have reasons that make me believe that nothing breaks the general law of equivalence" (A III, 6, 131). In summary, collision does not break with relativity.

In this case, what can be established absolutely is the cause or force of motion, which is measured by the effect or variation of distance that body $c$ can produce and remains the same whether we consider that body to be in motion or at rest. However, even if we concede this thesis, is it valid to conclude therefore that body $c$ exerts an action and is the cause of the change we perceived? Contrary to Leibniz's claims, we believe the reasons grounding this thesis are far from evident. In fact, we can accept his reasoning but reject his conclusion: for example, even if it is true that collision between bodies shows that something is acting, it is not necessarily the body itself exerting the action. It could be produced by another entity, as occasionalism defends. Indeed, we can accept the difference between force and quantity of motion and, simultaneously, the thesis that the cause of motion lies in a subject different from the particular bodies in motion; in his writings on physics, Leibniz offers no response to that position.

19 Many scholars read these claims as a defense of absolute motion; cf. Garber (2009, pp. 112-113) and Roberts (2003). For a compatibilist reading, cf. Jauernig (2008).

Manuscrito - Rev. Int. Fil. Campinas, v. 44, n. 1, pp. 98-130, Jan.-Mar. 2021. 
In his second argument Leibniz uses the paradigmatic case for studying relative motion in the $17^{\text {th }}$ century: something moving on a ship. In particular, he supposes a man on the deck walking at the same speed of the ship, but in the opposite direction. Thus the man moves in relation to the boat, but if we consider, for example, some external fixed points on the coast, he is at rest in relation to them. In this regard, Leibniz claims that despite the frame of reference chosen,
"we should say that he is in motion, because that man feels that he gets tired when he walks and that he can push or pull something in virtue of his motion; thus, he acts. Therefore, since we attribute motion to that in which the cause of change of situation is found, that is, to that which acts, we say that body $e$ [namely the man] moves even if he does not change the place that he has in the world in relation to the points we assumed" (A VI, 4, 2018-2019).

The general idea is similar to the first argument: the force that a body exerts can be established independently of the frame of reference. However, in this example, Leibniz grounds his conclusion in a different reason: an internal experience. Despite the apparent simplicity of this argument, it requires presumptions that go beyond natural philosophy; specifically, some theses of Leibniz's theory of knowledge ${ }^{20}$. But even if we concede that it can be so

20 Leibniz accepts two ways to demonstrate a the truth of a notion: first, a priori, that is, by an analysis that reduces the notion to its simple elements and shows that there are no contradictions between them; second, a posteriori, that is, by the experience, because the existence implies possibility (cf. A VI, 4, 589). 
demonstrated that we are truly causal agents in the world, the conclusion that Leibniz proposes as following from that does not seem well grounded. Although this argument could be better than the first in order to refute occasionalism since it shows that at least one body is a causal agent in the world, from this fact Leibniz cannot derive that force is inherent to bodies in general. As a consequence of reducing the argument to an internal experience, the proof cannot extend its conclusion to external bodies.

In summary, the main objective of these two arguments is to prove that the subject that causes the change of distance is the body itself. In Principia mechanica ex metaphysica dependere (1678-80/1), Leibniz claims explicitly that "it is a mistake to consider that the motion is conserved but not the force or reason of motion, which, despite it could be derived from God, we must not judged that it is in God himself, but that it is produced and conserved in things" (A VI, 4, 1980). Nevertheless, neither of Leibniz's arguments is conclusive: in the first, occasionalism remains as a valid interpretation of his dynamics; in the second, the conclusion is limited to one particular body and cannot reach the things that are studied in natural philosophy, namely bodies in general.

It is worth noting that Leibniz never made these arguments public. Furthermore, in the years after publication of the Brevis demonstratio, he stopped referring to this issue in his physical writings. In fact, it is absent from

According to Leibniz, most of human knowledge is acquired in the second way. On the one hand, notions as action or force (or identity, being, unity, and others) cannot be demonstrated a priori, but their demonstration relies in an internal or reflexive experience (cf. A VI, 4, 1572). On the other hand, Leibniz claims that this internal perception cannot be erroneous (cf. GP V, 221). 
Phoranomus seu de potentia et legibus naturae (1689), Dynamica de potentia (1690), and the Essais the dynamique (1692). This fact, however, does not imply that Leibniz gave up on solving the issue. On the contrary, the idea that forces should be placed in bodies themselves, and not in God or another kind of immaterial entity, would be a central topic in his metaphysical debates with occasionalism and Newtonians like Clarke. In fact, Leibniz himself links this problem with one of the main issues of his mature philosophy. But why did Leibniz begin to study this issue only in his metaphysical writings?

We believe that these first attempts to prove that particular bodies are true agents in nature taught Leibniz that the problem of which subject is really exerting the force cannot be established within natural philosophy. Even though Leibniz does not offer an explicit statement for this thesis, there are two main reasons that allow us to arrive to this conclusion. On the one hand, after 1681 Leibniz stops trying to establish from the consideration of bodies in motion that force is inherent to particular bodies themselves ${ }^{21}$. On the other hand, he explicitly

${ }^{21}$ It should be noted that the introduction of the a priori argument
in the Dynamica de potentia and the correspondence with Papin and
De Volder could be challenging for our interpretation, for in this
particular proof Leibniz arrives to the correct measure of the
force from a consideration of the action of a body in uniform
rectilinear motion. In order to present this argument, Leibniz
introduces a distinction between violent action and formal action. The
first one is conceived as an action that consumes its force to
overcome exterior obstacles, such as happens, for example, in the
ascension of a body in a resisting medium (cf. GP II, 190). The
second one is conceived as an action that does not consume its
force insomuch it has no exterior obstacle to overcome, such as
happens, for example, in a body that moves on a horizontal plane
without resistance (cf. GP II, 190). The a priori argument Manuscrito - Rev. Int. Fil. Campinas, v. 44, n. 1, pp. 98-130, Jan.-Mar. 2021. 
acknowledges that the distinction between force and quantity of motion is compatible with other metaphysical theses, such as occasionalism. Indeed, as Leibniz writes to Catelan, once the difference between force and quantity of motion is accepted, "we have to admit in bodies something different from their quantity and speed, unless we want to negate to them all potency of action" (GP III, 48). Malebranche and De Volder are two examples of philosophers that, after long debates, concede to Leibniz his measure of the force, but negate to bodies the potency of action. In this sense it is worth noting that, at least after 1681, Leibnizian dynamics does not need nor want to solve that issue because for grounding dynamics it is sufficient to prove that force of motion could be measured in a different way than quantity of motion, regardless of which subject is exerting that force. Therefore, Leibniz seems to dissociate the problem of the cause of motion from the problem of the subject of motion: while the first issue is necessary for establishing dynamics, the second one demands another kind of approach: natural philosophy finds here a boundary that only metaphysics should overcome. In summary, even though the problem of the subject of change plays a role in the discovery of dynamics, as we have claimed in the first

considers specifically the formal action, which Leibniz also called free action since it is the action free from external obstacles. The fact that we must only change the medium in which a force operates in order to pass from one consideration of the action to the other is crucial to understand how is possible to have two different kinds of arguments (the a posteriori and the a priori) for measuring the same force. Despite it goes beyond the interest of our paper, we believe that Leibniz does not commit himself with a stronger metaphysical thesis in the a priori argument. But this problem requires to be considered in length and escapes our current goal. 
section, we believe that after 1681 Leibniz became aware that this particular issue plays no role in its justification.

\section{Abbreviations}

A: Leibniz, G. W., Sämtliche Schriften und Briefe, ed. Deutsche Akademie der Wissenschaften zu Berlin, Berlin: AkademieVerlag, 1923-.

AT: Descartes, R., Ouvres, eds. C. Adam and P. Tannery. Paris: Vrin, 1964-1976.

DCC: Leibniz, G. W., La réforme de la dynamique: De corporum concursu (1678) et autres textes inédits, ed. Fichant, Paris: Vrin, 1994

GM: Leibniz, G. W., Mathematische Scbriften, ed. C. I Gerhardt, 7 vols. Berlin: Asher, 1848-1863.

GP: Leibniz, G. W., Die philosophischen Schriften, ed. C. I. Gerhardt, 7 vols. Berlin: Weidmann, 1875-90.

Huygens: Huygens, Ch., Oeuvres complètes de Christiaan Huygens, eds. La Société hollandaise des sciences, 22 vols., The Hague: M. Nijhoff, 1888-1950.

\section{References}

ANTOGNAZZA, M., Leibniz: An Intellectual Biography, Cambridge, Cambridge Universit Press, 2009.

BELAVAL, Y. Etudes leibniziennes, Paris, Gallimard, 1976

BERNSTEIN, H. "Leibniz and Huygens on the 'Relativity' of Motion", in: Studia Leibnitiana, 13: pp. 97-113, 1984.

BROWN, G, "Quod ostendendum susceperamus: What did Leibniz undertake to Show in the Brevis 
Demonstratio?", in: Studia Leibnitiana Sonderhefte, 13: pp. 122-137, 1984.

COSTABEL, P. Leibniz et la dynamique. Le texte de 1962, Paris, Hermann, 1981

DUCHESNEAU, F. La dynamique de Leibnir, Paris, Vrin, 1994.

DUGAS, R., Histoire de la mécanique, Neuchatel, Griffon, 1950.

FICHANT, M. 'La 'réforme' leibnizienne de la dynamique, d'après des textes inédits", in: Akten des II. Internationaler Leibniz-Kongresses, Bd. II, Studia Leibnitiana Supplementa, 13: 195-214, 1974.

GALE, G. "The Concept of Force and its Role in the Genesis of Leibniz' Dynamical Viewpoint", in: Journal of the History of Philosophy, 26 (1): pp. 45-67, 1988.

GARBER, D. Leibniz: Body, Substance, Monad, Oxford, Oxford University Press, 2009.

GUEROULT, M. Dynamique et métaphysique leibniziennes, Paris, Belles Lettres, 1934.

HANNEQUIN, A. "La première philosophie de Leibniz", in A. HANNEQUIN. Etudes d'histoire des sciences et d'histoire de la philosophie, Paris, Alcan, 1909.

HOFMANN, J. Leibniz in Paris 1972-1976. His Growth to Mathematical Maturity, Cambridge, Cambridge University Press, 1974.

ILTIS, C. "Leibniz and the Vis Viva Controversy", Isis, 62: pp. 21-35, 1971.

JAUERNIG, A. "Leibniz on motion and the Equivalence of Hypoteses", in: Leibniz Review, 18: pp. 1-40, 2008.

LEIBNIZ, G. W. The Labyrinth of the continuum: writings on the continuum problem, translated by R. ARTHUR, New Haven/London, Yale University Press, 1992.

LEIBNIZ, G.W., Philosophical Papers and Letters, translated by L. LOEMKER, Dordrecht-Boston, Reidel, 1969. 
ROBERTS, J. "Leibniz on Force and Absolute Motion", in: Philosophy of Science, 70 (3): 553-573, 2003.

ROBINET, A. "Dynamique et fondements métaphysiques", in : Studia Leibnitiana Sonderheft, 13: pp. 1-25, 1984.

ROBINET, A. Architectonique disjonctive, automates systémiques et idéalité transcendentale dans l' cuvre de G. W. Leibniz, Paris, Vrin, 1986.

SHIMONY, I. "Leibniz and the vis viva Controversy", in: M. DASCAL (ed.), The Practice of Reason. Leibniz and his Controversies, Amsterdam/Philadelphia, John Benjamins Publishing Company, pp. 51-74, 2010.

THO, T. Vis, vim vi: Declinations of Force in Leibniz's Dynamics, Cham, Switzerland, Springer International Publishing, 2017.

$(\mathrm{cc}) \mathrm{EY}$ 